\title{
Urdimento
}

Revista de Estudos em Artes Cênicas

E-ISSN: 2358.6958

\section{Calles, iglesias y plazas: Los espacios en las manifestaciones de teatralidad andina}

\author{
Rodrigo Benza Guerra
}

\section{Para citar este artigo:}

GUERRA, Rodrigo Benza. Calles, iglesias y plazas: Los espacios en las manifestaciones de teatralidad andina. Urdimento, Florianópolis, v. 2, n. 38, ago./set. 2020.

DOI: http:/dx.doi.org/10.5965/14145731023820200009

Este artigo passou pelo Plagiarism Detection Software | iThenticate 
Calles, iglesias y plazas: Los espacios en las manifestaciones de teatralidad andina

\author{
Rodrigo Benza Guerra1
}

\begin{abstract}
Resumen
El presente texto tiene como objetivo presentar y describir el uso y funciones de los espacios en los que se desarrollan las manifestaciones de teatralidad andina. Concebimos las manifestaciones de teatralidad andina como aquellas danzas que forman parte de los rituales y fiestas desarrolladas en los andes. Esta descripción es presentada a la luz de los conceptos de continuum (Schechner) y liminalidad (Dieguez) y parte, principalmente, de mi propia experiencia como asistente en la fiesta de la Virgen del Carmen en Paucartambo (Cusco, Perú) y de acompañante de una comparsa en la fiesta de la Virgen de Cocharcas en Sapallanga (Junín, Perú).
\end{abstract}

Palabras clave: Teatralidad andina. Espacio escénico. Ritual. Performance.

Ruas, igrejas e praças: Os espaços nas manifestações de teatralidade andina

\title{
Resumo
}

O presente texto tem por objetivo apresentar e fazer uma descrição da utilização e funções dos espaços nos quais se desenvolvem as manifestações de teatralidade andina. As manifestações de teatralidade andina são concebidas como aquelas danças que formam parte dos rituais e festas desenvolvidas nos andes. Esta descrição é apresentada a partir dos conceitos de continuum (Schechner) e liminalidade (Dieguez) e surge, principalmente, da minha própria participação na festa de Virgen de Carmen em Paucartambo (Cusco, Peru) e como ajudante de um bloco de dança na festa da Virgem de Cocharcas em Sapallanga (Junín, Peru).

Palavras-chave: Teatralidade andina. Espaço cênico. Ritual. Performance. 
Streets, churches and squares: The spaces of andean theatrical manifestations

\begin{abstract}
The purpose of this text is to present and describe the use and functions of the spaces in which Andean theatrical manifestations take place. We conceive Andean theatrical manifestations as those dances that form part of the rituals and festivals developed in the Andes. This description is presented in light of the continuum (Schechner) and liminality (Dieguez) concepts, and comes mainly from my own experience as a participant in the Virgen del Carmen festival in Paucartambo (Cusco, Peru) and a colaborator of a dance troupe at the Feast of the Virgin of Cocharcas in Sapallanga (Junín, Peru).
\end{abstract}

Keywords: Andean theatricality. Scenic space. Ritual. Performance. 
Cuando hablamos de espacio escénico, habitualmente pensamos en un espacio específico, ya sea un teatro, o algún lugar "alternativo" acondicionado para la realización de una experiencia escénica como una calle, un edificio abandonado o un templo. Sin embargo, existen fiestas y rituales populares que duran varios días durante los cuales, en distintos espacios se presentan diversas manifestaciones de teatralidad. En este texto pretendo describir los diferentes espacios y sus funciones en las manifestaciones de teatralidad andina, a la luz de los conceptos de continuum entre eficacia y entretenimiento planteado por Richard Schechner y de liminalidad de acuerdo a lo planteado por Ileana Dieguez. Estas descripciones están basadas en mi propia vivencia en dos manifestaciones en particular: La fiesta de la Virgen del Carmen en Paucartambo - Cusco (Perú) que se realiza del 15 al 17 de julio, y la fiesta de la Virgen de Cocharcas en Sapallanga - Junin (Perú) que se realiza la segunda semana de setiembre.

Con manifestaciones de teatralidad andina, me refiero a aquellas expresiones escénicas que surgen principalmente durante la época colonial ${ }^{2}$ y que se componen de la fusión de elementos prehispánicos (taki³) y expresiones escénicas y rituales traídas por los españoles. Estas manifestaciones cuyo formato principal suele ser la danza, forman parte de diversos rituales y festividades, muchos de ellos ligados a las fiestas católicas en honor a santos, santas y vírgenes. Estas danzas, además, tienen un fuerte carácter teatral, donde hay personajes o presencias escénicas, usualmente enmascarados; están acompañadas de músicos que las siguen a lo largo de toda la fiesta, y, además de estar ligadas a momentos rituales, la fiesta y el juego son imprescindibles.

Con la llegada de los españoles, las danzas y los rituales Incas tomaron dos rumbos diferentes. Por un lado, como menciona Luis Millones (1992) eran percibidos como peligrosos y, por lo tanto, eran perseguidos o censurados. Por

Aunque algunas danzas, como los Huacones de Mito (Junin) son prehispánicas, y otras, como el Auqa Chileno, son republicanas.

El taki "era una representación integral -conformada por canciones, personajes enmascarados, parlamentos o textos, danzas, etcétera-, que se presentaba en el Tahuantinsuyo y en otras culturas preincaicas, para contar historias, sucesos, mitos, celebrar diversos acontecimientos o rituales ligados a la vida social, natural y productiva" (Vasquez, 2007, p. 10). Sobre el taki, ver también Millones, 1992 y Rubio, 2016. 
otro lado, fueron usados por la iglesia católica como un camino para evangelizar:

Desde la Colonia, la influencia cristiana europea en la religiosidad andina fue marcada por el mestizaje. El santoral traído por los españoles fue reinterpretado y sincretizado por la población local, de este modo, la relación entre la imagen de la Virgen María, madre de Jesús de Nazaret, y la Pachamama o Madre Tierra, es una constante en las tradiciones del mundo andino. (Ministerio de Cultura, 2014, p. 2).

De parte de la población indígena, durante la colonia, los distintos santos, patrones y vírgenes católicas se fueron relacionando con divinidades y costumbres locales, prehispánicas. Santiago apóstol, por ejemplo, está relacionado a Illapa, "Dios milenario de origen pre-inca [...] asociado al rayo, el trueno y las tempestades" (Rubio, 2008, p. 165). Para la población indígena era tan fuerte el vínculo entre Santiago e Illapa que, para que una imagen de Santiago tenga validez, debía contener pedazos de metal fundidos por un rayo: "entonces así recién tiene validez la imagen para los campesinos, porque sino es una imagen cualquiera, entonces recién es Santiago para ellos." (Cayo apud Rubio, 2008, p. 169).

En Cusco, la procesión de los santos durante la celebración del Corpus Christi está emparentada con el paseo que hacían de las momias Incas antes de la llegada de los españoles. Como lo presenta Miguel Rubio (2008, p. 164),

[...] cuando los españoles llegaron al Cusco en 1532, se sorprendieron de ver las procesiones de los cuerpos momificados de los jerarcas incas. A esos orígenes se remonta este recorrido de vírgenes y santos católicos que en número de quince atraviesan las calles como antes lo hicieron las momias de los incas.

En los festejos del Corpus Christi se sienten el viejo y el nuevo mundo como parte de una celebración de la sagrada eucaristía en la que están presentes la pachamama, el tayta inti ${ }^{4}$ y otras divinidades andinas.

Por otro lado, muchos de los espacios de culto elegidos por los católicos están relacionados con los espacios rituales prehispánicos. Tal vez uno de los ejemplos más claros de esto sea el templo del Qoricancha en el centro del Cusco donde se puede apreciar la construcción hispana encima de un templo Inca. Otro

${ }^{4}$ Padre (Dios) sol 
ejemplo muy claro de esto son las cruces colocadas en las puntas de los cerros más altos de determinada localidad. Siendo la madre tierra, la Pachamama, una de las divinidades más importantes del Incanato, los cerros, los apus, eran los protectores locales. A estos cerros se realizaban peregrinaciones y los católicos se valieron de estos rituales locales para imponer su religión de distintas formas, como colocando cruces en las puntas de dichos cerros. Otra forma fue incorporando las danzas autóctonas a los rituales y eventos católicos. Por ejemplo, muchas veces antes de la presentación de un auto sacramental en el atrio de una iglesia, se realizaba un pasacalle con danzas locales para atraer a la población indígena. En palabras de Luis Millones (1992, p. 23):

Resulta mucho más simple suponer que las festividades andinas no desaparecieron con la Conquista. Palidecieron por falta de recursos económicos y sociales, pero se restablecieron al incorporarse al ceremonial católico, que decidió asimilarlas al menos en parte para ensanchar la convocatoria entre los nuevos cristianos.

Las danzas no son un accesorio, sino que, por un lado, son el medio de supervivencia de las expresiones prehispánicas que se presentan en las nuevas expresiones rituales y, por otro, las formas de organización del movimiento de la misma danza son una representación de las peregrinaciones realizadas desde tiempo inmemoriales:

Deborah Poole (1991a y b) ve en las danzas la expresión de la fuerza y vitalidad de la cultura andina. A través de la ejecución de las danzas en contextos festivos, los indígenas mantienen el control ritual sobre las fuentes de lo sagrado. Poole, quien centró su investigación en el departamento del Cusco, señala la importancia ritual y social de las danzas en las peregrinaciones. Primero como representación simbólica de toda la comunidad frente a una divinidad, siendo las intermediarias que buscan agradar a la divinidad transmitiendo la fe de toda su unidad social. Luego, como relacionadas con la estructura social de la comunidad a través del sistema de cargos. Mas su enfoque se centra en el análisis coreográfico, del cual concluye que los movimientos interiores de la comparsa - las coreografías- y exteriores -los desplazamientos en el espacio- son una réplica de los sentidos fundamentales del peregrinaje, los cuales están inmersos en patrones culturales quechuas. (Lecaros-Terry, 2001, p. 130). 
Por otro lado, muchas de las danzas y personajes que se presentan en las distintas fiestas representan -generalmente en forma de parodia- segmentos de la sociedad. De esta manera en las regiones de Junín y Pasco (andes centrales), la Chonguinada, por ejemplo, surge de la imitación de los bailes de Minuet de los españoles durante la época de la colonia, y el Chuto, acompañante de los chonguinos, representa al campesino, al indígena. En Cusco, encontramos la danza de los Majeños que representa a los comerciantes de licor que llegaban del valle de Majes (Arequipa), o a los Doctorcitos (Siqllas o Wayras) que representan una parodia de los doctores - abogados que imparten "justicia".

Estas danzas continúan desarrollándose en fiestas religiosas o celebraciones locales que suelen durar varios días. En los días que dura la fiesta, el pueblo se transforma y sus distintos espacios se resignifican de acuerdo a las necesidades de la fiesta. Los elementos escénicos (danza, teatro, música), el ritual, la fiesta y el juego conviven y se alternan generando un espacio de convivio en el que todos los involucrados, danzantes, devotos y visitantes, se convierten en participantes.

Las distintas comparsas tienen una programación determinada y ocupan diversos espacios que cumplen funciones variadas. En primer lugar, está el espacio del local del grupo, "cargo" o "casa de cargo". Este espacio es la casa de la comparsa durante el tiempo de la fiesta. Es donde se preparan y ensayan, y también donde reciben a los invitados en los distintos días. Luego están las calles del pueblo, que durante el tiempo de la fiesta asumen el carácter festivo y una teatralidad orgánica con las comparsas de distintas danzas, por un lado, y las procesiones, por otro. El atrio de la iglesia y la iglesia misma son los espacios que más conservan la ritualidad católica y en el que los danzantes se "desnudan", se quitan la máscara, presentándose como individuos y no solo como danzantes. Tal como veremos más adelante, dependiendo de la fiesta, también son relevantes espacios como plazas, lozas deportivas, el cementerio, entre otros, que se convierten en escenarios.

Toda la experiencia de la fiesta con los elementos rituales y teatrales conviviendo y alternándose, tiene un fuerte contenido liminal en el sentido propuesto por Ileana Dieguez, quien percibe lo liminal como "tejido de constitución 
metafórica: situación ambigua, fronteriza, donde se condensan fragmentos de mundos, perecedera y relacional, con una temporalidad acotada por el acontecimiento producido, vinculada a las circunstancias del entorno" (Dieguez, 2014, p. 64). Por otro lado, el hecho de que la danza sea percibida primordialmente por su contenido estético o espectacular, o que constituya una vivencia ritual, es flexible y está determinado tanto por la intención de los danzantes como por el nivel de devoción que tenga el testigo del hecho escénico-ritual, que puede estar más hacia el lado ritual o al de espectador.

En este sentido, la experiencia en la fiesta es un constante ir y venir a través del continuum entre la eficacia del ritual y el entretenimiento del teatro (danza / performance). Como dice Richard Schechner (2005, p. 116),

Eficacia y entretenimiento no son tan opuestos entre sí, en realidad, ambos forman los pilares de un continuum [...]. La polaridad básica es entre eficacia y entretenimiento, no entre ritual y teatro. Que uno llame a un performance "ritual" o "teatro" depende principalmente del contexto y la función. Un performance es llamado teatro o ritual según donde es presentado, por quién y bajo qué circunstancias [...]. Ningún performance es puramente eficaz o puramente entretenimiento. ${ }^{5}$

Por lo tanto, la ubicación del hecho escénico/ritual en el continuum resulta de una combinación entre la intención de los danzantes y la posición del testigo. Es decir, dependiendo de quién esté testimoniando el hecho escénico/ritual, este estará colocado más hacia el ritual o hacia el espectáculo. En esa misma línea, los espacios determinan -hasta cierto punto- si el hecho escénico busca ser más ritual o más espectacular durante los días de la fiesta. De esta manera, hay espacios físicos, como la iglesia, que están destinados al ritual - a pesar de que un no creyente, por ejemplo, lo pueda seguir percibiendo desde el entretenimiento - y otros que están destinados al entretenimiento en sí o al espectáculo como el caso de los espacios de los concursos.

${ }^{5}$ Efficacy and entertainment are not so much opposed to each other; rather they form the poles of a continuum [...]. The basic polarity is between efficacy and entertainment, not between ritual and theater. Whether one calls a specific performance "ritual" or "theater" depends mostly on context and function. A performance is called theater or ritual because of where it is performed, by whom, and under what circumstances [...]. No performance is pure efficacy or pure entertainment. (Tradução nossa) 
En las siguientes líneas quisiera presentar los espacios en dos fiestas en particular: La fiesta de la Virgen de Cocharcas en Sapallanga (Junín) y la fiesta de la Virgen del Carmen en Paucartambo (Cusco), para después tomar algunos elementos de análisis a la luz de los conceptos de liminalidad y continuum. He escogido estas fiestas porque son las dos en las que yo he participado de forma más intensa y, por lo tanto, el análisis partirá de mi propia experiencia en las mismas.

\section{La Virgen de Cocharcas en Sapallanga ${ }^{6}$}

Sapallanga es un distrito que se encuentra a 10 kilómetros al sur de la ciudad de Huancayo, que es una de las ciudades más importantes de los andes centrales. En la segunda semana de setiembre de todos los años se celebra la fiesta de la Virgen de Cocharcas en la que participan comparsas de distintas danzas como la Capitanía, Apu Inca, Ccalachaqui, Negrería y Chonguinada.

Fue a partir de esta última danza, la Chonguinada, que conocí la fiesta de La Virgen de Cocharcas en Sapallanga. Interesado en aprender de las manifestaciones teatrales populares andinas, junto al actor Ricardo Delgado, elaboré el proyecto de investigación Posibilidades de creación escénica a partir de la danza La Chonguinada como ejemplo de teatralidad andina?. Para el desarrollo de la investigación nos involucramos con una comparsa de Chonguinada llamada Pasiones Huanca compuesta principalmente por migrantes de Huancayo asentados en la ciudad de Lima, y que todos los años participan, por devoción, de la fiesta en cuestión. Ricardo entró a aprender la danza durante varios meses y, en setiembre, fuimos a Sapallanga.

Existen muchos aspectos a partir de los cuales podríamos abordar el análisis

\footnotetext{
${ }^{6}$ Para saber más sobre esta fiesta, se puede consultar

https://cdn.www.gob.pe/uploads/document/file/209756/rvm_047-.pdf

Este proyecto fue ganador del Concurso Anual de Proyectos de Investigación de la Pontificia Universidad Católica del Perú en el año 2017. En el proceso de investigación, y por lo tanto en la gestación de estas
} reflexiones, participaron Ricardo Delgado, Gabriela Rojas y Laura Ortiz. 
tales como la descripción o historia de la danza ${ }^{8}$ o la organización interna de las comparsas, sin embargo, en esta ocasión me centraré en el tema de los espacios y sus usos durante la fiesta:

\section{Local del grupo}

Cada comparsa o grupo de baile alquila un local amplio durante los días de la fiesta. Como mencioné líneas arriba, este local se convierte en la casa del grupo, albergando a los bailarines, la orquesta ${ }^{9}$, las personas de apoyo a la comparsa y los amigos. Valga la aclaración de que este no es un espacio de alojamiento, sino un espacio de encuentro, de preparación y de ensayo, y es también el espacio para recibir a los invitados. Es común recibir gente que llega a visitar de forma espontánea, la cual es bienvenida y, dependiendo del momento en el que llega, puede ser recibida con comida y cerveza.

\section{Las calles}

Las calles del pueblo, principalmente las aledañas a la iglesia principal, se inundan de puestos de comida y otros productos, y se llenan de visitantes que van tanto para expresar su devoción a la Virgen de Cocharcas como para ver y disfrutar de las distintas danzas. A su vez, el pueblo se llena de colores, de danzantes enmascarados y variados personajes que, a través de la danza y el juego, demuestran su devoción a la Virgen.

En el momento en que todos los danzantes de la comparsa están listos, con los trajes (vestuario) bien puestos, la comparsa sale del local y va caminando junta hasta un punto en el cual el director (en el caso de Pasiones Huanca, el profesor Julio) determina que se va a bailar el pasacalle. Los danzantes se colocan en sus

8 Para saber más sobre la danza se puede consultar Lecaros-Terry, 2001; Municipalidad Provincial de Junín, 2010.

${ }^{9}$ Cada comparsa contrata a una banda u orquesta musical que la acompañará durante todos los días de la fiesta. 
posiciones, la orquesta empieza a tocar y los danzantes ejecutan los movimientos de la danza que han sido preparados para los traslados. Una vez terminada la coreografía, caminan algunas cuadras más y repiten la danza.

Durante todo el tiempo, los danzantes están acompañados de algunos Chutos, que son personajes que cumplen varias funciones: hacen un contrapunto más "relajado" con una danza libre, juegan e interactúan con el "público" y cuidan a los danzantes.

Cuando estos traslados son para ir hacia la iglesia, es común encontrarse con otra comparsa de cualquiera de las danzas representativas de la fiesta y que las bandas de música entren en una especie de duelo musical.

\section{El frontis de la iglesia}

Una vez que la comparsa llega al frente de la iglesia, donde se ha asignado un espacio especial para que las comparsas presenten sus coreografías en honor a la Virgen, los danzantes asumen una actitud más solemne. Se arreglan los trajes, se colocan las máscaras ${ }^{10}$, y danzan para la Virgen la coreografía completa en su honor.

Este es el espacio "oficial” para que las comparsas de danzantes puedan expresar su fe. A pesar de que hay mucha gente alrededor del espacio observando las coreografías, en este momento la danza no está diseñada para ser un espectáculo, sino un acto de devoción. No se danza para las personas, para el público, se danza para la Mamacha Cocharcas ${ }^{11}$.

Una vez terminada la coreografía, la comparsa regresa a su local, siempre parando de cuándo en cuándo para danzar.

Las visitas de las comparsas a la iglesia son aleatorias y se puede ir más de una vez al día.

${ }^{10}$ En la chonguinada solo los hombres usan máscara.

${ }^{11}$ El "cha" es un sufijo diminutivo en quechua. "Mamacha", por lo tanto, significa "mamita". 


\section{Casas}

Los danzantes de estas fiestas bailan por devoción, principalmente, y no reciben un pago por hacerlo. Inclusive, cada quien cubre su pasaje, estadía y el costo del alquiler del vestuario, por lo menos en el caso de la danza la Chonguinada. En el caso de Pasiones Huanca, en concreto, el profesor Julio, con el apoyo de la familia, los amigos y algunos de los integrantes de la comparsa, se encarga de conseguir los recursos para el alquiler del local, la comida y la cerveza, principalmente.

Una de las formas más comunes de cubrir la alimentación y la cerveza es conseguir una invitación de alguien allegado al grupo y, en retribución, el grupo baila la Chonguinada en la casa. Es importante entender que la familia que ofrece el desayuno o el almuerzo, debe alimentar y dar cerveza a más de 50 personas entre bailarines, músicos e invitados,

En las casas en las que la comparsa es recibida, se hace fiesta con diversos ritmos como el huaylash, el santiago y la cumbia y, en determinado momento, el grupo se coloca en la formación de la coreografía y se baila la misma coreografía que se bailó frente a la iglesia.

Los anfitriones reciben a la comparsa por diversos motivos. Puede ser como una forma de demostrar la fe hacia la Virgen, por reciprocidad con el grupo, por amistad, o - más probablemente - una suma de las anteriores. En todo caso, es un honor recibir una comparsa de baile en tu casa en el contexto de la fiesta.

Por otro lado, el baile que se ofrece en retribución debe mostrar gran gratitud y respeto hacia los anfitriones. Quiero aquí compartir una historia de otra fiesta, también en honor a la virgen de Cocharcas, pero en el mismo distrito de Cocharcas, que forma parte de Sapallanga. Esta fiesta se da una semana después de la de Sapallanga y es más pequeña, más familiar.

Estábamos yendo con la comparsa a recibir el desayuno en la casa de uno de los vecinos, y el encargado del grupo ordenó tocar un Santiago. Las fiestas de Santiago son en los meses de julio y agosto. En un momento, el anfitrión toma la 
palabra y llama la atención del grupo: "estamos en setiembre, es tiempo de Chonguinada. Las fiestas de Santiago ya terminaron. Por lo tanto, es una falta de respeto que ustedes vengan a mi casa bailando un Santiago en lugar de venir con Chonguinada".

Los códigos son compartidos y conocidos por bailarines y no bailarines, y cada cosa tiene su tiempo, su lugar y sus formas. En ese sentido, podemos afirmar que es la combinación de lugar y tiempo lo que conforma y le da marco a la experiencia.

\section{El concurso}

Parte de esta fiesta es el concurso de baile. Para algunos participantes, la motivación del concurso es incluso mayor que la de la devoción por la Virgen. En Sapallanga, se coloca un escenario donde se encuentran el animador y los músicos, y al nivel del piso se deja un gran espacio para la danza. Frente a dicho espacio están las cabinas de los jurados y en el frente y ambos costados hay graderías para el público. Este es un espacio diseñado para que las danzas sean un espectáculo. Inclusive, aquellos que quieren entrar a verlas tienen que pagar una entrada.

Es en este momento, además, que se presenta la coreografía completa, incluyendo una representación teatral en el medio que muestra la historia de cómo llegó la Virgen de Cocharcas a Sapallanga.

\section{Espacios o significados especiales}

La fiesta por la Virgen de Cocharcas, así como la de la Virgen del Carmen, tiene un mito de origen que está relacionado con la forma como llegó la Virgen al pueblo. La historia, recopilada en el siglo XVII, cuenta que Sebastián Quimichu estaba viajando de pueblo en pueblo con una pequeña imagen de la Virgen de Copacabana (Puno) para recolectar dinero para construirle un templo en su pueblo 
natal: Cocharcas (Apurimac). Quimichu se quedó dormido y cuando despertó no encontró la imagen de la Virgen. Luego, pobladores locales la encontraron adherida a la piedra pero no pudieron sacarla, hasta que llegaron unos niños danzando la danza del Ccalachaqui y solo así consiguieron sacarla (Ver Ministerio de Cultura, 2014).

Me parece relevante esta historia porque las danzas no se presentan como un adorno o un accesorio, sino que es gracias a las danzas que, según el mito, la Virgen accedió a ser trasladada a la Iglesia del pueblo.

Por otro lado, en este caso también hay una relación entre la construcción del espacio ritual, las creencias prehispánicas, y los mitos de origen:

[...] el valor simbólico de esta festividad se condice con la importancia que se otorga a las edificaciones y espacios naturales asociados a ella, que son muestra de la relación compleja y rica entre las creencias andinas y europeas que confluyeron durante la Colonia. Así, se aprecia que la Capilla fue construida al lado del manantial en donde, según la tradición, se vio por primera vez la imagen de la Virgen, y a este manantial se le adjudican poderes curativos relacionados a la Virgen y a sus dones, del mismo modo que existía, en el panteón andino, una sacralización de la naturaleza." (Ministerio de Cultura, 2014, p. 6).

Como se puede ver, las manifestaciones de teatralidad andina son complejas y pueden cumplir diversas funciones dependiendo del momento y del lugar. Además, son manifestaciones que abrazan lo sagrado, lo ritual, lo espectacular, la reciprocidad, la identidad y la fiesta como parte de un todo que convive, se alterna y se combina.

El uso de espacios de la fiesta de la Virgen de Cocharcas en Sapallanga es un ejemplo del modelo que tienen muchas de las fiestas a lo largo de todo el territorio peruano. A continuación, presentaré la Fiesta de la Virgen del Carmen en Paucartambo que tiene una serie de particularidades en diversos aspectos, incluido el espacial, que la hacen muy rica y especial. 


\section{Fiesta de la Virgen del Carmen en Paucartambo - Cusco ${ }^{12}$}

En este caso, el análisis de la fiesta parte de mi propia experiencia como "espectador" en tres ocasiones diferentes entre los años 2002 y 2019, además de la cercanía e intercambio con fieles (mi hermana es devota) y estudiosos de la teatralidad de esta fiesta como Miguel Rubio, director del grupo Yuyachkani.

Paucartambo es un pueblo en la región de Cusco muy especial porque es el punto medio entre la ciudad del Cusco y la selva. Por lo tanto, es una zona de intercambio de productos y encuentro, y durante la colonia era una región muy rica: "En la época de la Colonia, la hacienda se convirtió en el núcleo económico, tanto en la sierra como en la selva de Paucartambo, centrando su producción en la explotación agrícola y ganadera (Mörner, 1977)” (Cánepa, 1998, p. 42). Existen diversas versiones sobre la llegada de la Virgen a Paucartambo ${ }^{13}$, pero se puede encontrar cierta coincidencia en que la imagen de la Virgen del Carmen estaba siendo llevada hacia la puna, hacia las alturas, pero en el camino cae al río y se va camino a la selva para, finalmente, terminar como "invitada" en la iglesia de la Virgen del Rosario en el pueblo de Paucartambo. Algunas versiones alegan que la imagen sufrió un ataque por parte de los Ch'unchus (selva) y es por eso que, por la culpa, estos se convirtieron en sus guardianes. Otros dicen que la cabeza de la Virgen apareció flotando en el río.

La fiesta, cuyos días centrales son el 15, 16 y 17 de julio, consiste en la "lucha" entre los Qhapac qolla (de la puna) y los Qhapaq ch'unchu (de la selva) por la custodia de la Virgen.

Miguel Rubio comparte la versión de los Qhapaq ch’unchu:

${ }^{12}$ Para entender mejor el carácter teatral de esta fiesta, consultar Rubio, 2016.

13 Ver Cánepa, 1998; Vásquez, 2014; Rubio, 2016 
La memoria cuenta que en 1700 hubo una apropiación de sus tierras y los españoles llevaron a la Virgen del Carmen como la imagen a la que le rendían culto. Los Ch'unchus un día atacaron las haciendas y una flecha le cayó a la Virgen. Entonces, por temor, arrojaron su cabeza al río que pasó a llamarse río Madre de Dios.

El rey Chonta Quiru no podía dormir después del ataque a la Virgen y soñaba con una mujer hermosa que le decía que vaya por un camino y le decía que cuando la encuentre su pueblo tendrá paz. Así llegaron a Paucartambo donde los Ch'unchus encontraron a la Virgen y decidieron ser sus eternos guardianes. (Rubio en Benza, 2007).

Todos los años, entonces los Qhapac qolla intentan recuperar a la Virgen y se enfrentan con los Qhapaq ch'unchu. Esto es relevante porque algunos de los espacios de la fiesta están determinados por este argumento, por este conflicto escénico.

Incluidas las dos comparsas mencionadas, en total son alrededor de 20 danzas diferentes que cumplen funciones variadas o representan segmentos sociales en el desarrollo de la fiesta, durante la cual, prácticamente todo el pueblo se convierte en un escenario compartido en el que conviven las comparsas, los pobladores, los fieles y los turistas:

O vasto cenário que dá origem à festa inclui toda a geografia desse povoado de serra. O espectador assiste a um explosivo transbordamento de teatralidade viva e em movimento, em que são combinados signos procedentes do passado com outros mais recentes. O conflito que as danças apresentam parece ter origem em um período anterior à conquista espanhola, e há signos que aludem a tempos mais remotos. (Rubio, 2016, p. 16).

La “representación” empieza cuando las comparsas hacen su entrada al pueblo.

1. El ingreso

Las comparsas presentes en la fiesta llegan al pueblo desde sus lugares de procedencia. Pero estos lugares de procedencia son de los personajes de las 
danzas, de su lugar "ficcional” de origen, y no del lugar de procedencia del danzante o de la danza en sí, porque todas las danzas son oriundas del mismo Paucartambo.

Paucartambo es un pueblo que tiene dos entradas principales: una que da a la selva y otra que da a la puna. De esta manera, las comparsas ligadas a la selva, como los Qhapaq ch'unchu o los Chucchư ${ }^{14}$, hacen su entrada al pueblo por la entrada que da a la selva, mientras que las comparsas de la sierra, como los Qhapaq qolla, hacen su entrada por el camino de la puna. Por su lado comparsas "locales" como la de los Panaderos, salen de las panaderías donde están localizados los hornos tradicionales. De esta manera, el carácter representacional de esta fiesta comienza, valga la redundancia, desde el inicio.

\section{Los cargos}

Los locales de cada comparsa son llamados "cargo" y, tal como ya se ha descrito, son espacios amplios en los que las comparsas se preparan y reciben a sus invitados. En esta fiesta, la costumbre es que cada año se designa un cargo (carguyoc o mayordomo) que también es el nombre que se le da a la persona encargada de conseguir todo lo necesario para la participación de la comparsa en la fiesta: local, comida, bebida, la banda de músicos. En este caso, las comidas se realizan en el mismo cargo y es muy común que lleguen invitados permanentemente. En los cargos también se realizan fiestas durante las noches que dura la celebración.

Existe también la costumbre, por parte de las comparsas, de visitar los cargos de las otras. De esta manera, la comparsa visitante entra bailando, presentando su respeto y homenaje, y la comparsa local, a su vez, baila en retribución:

Las comparsas se visitan unas a otras creando nuevos vínculos e incidentes que dan a la fiesta su característica de cultura viva que evoluciona a través de los años. La tradición de hospitalidad hace que, en lo posible, los mayordomos acojan a cualquier visitante o a un turista, como propio de la casa, dándoles de comer y beber como a cualquier otro integrante de la danza. (Perez en Vásquez, 2014, p. 206).

\footnotetext{
${ }^{14}$ La danza de los Chucchu representa a aquellos que regresan de la selva y se han contagiado de paludismo.
} 


\section{La calle}

Las calles del pueblo se ven permanentemente inundadas de comparsas y bailarines enmascarados durante los días de la fiesta. A veces las comparsas están trasladándose de un lado a otro simplemente caminando, o a veces lo hacen danzando o jugando con los transeúntes. Las calles son también las que acogen la procesión de la Virgen que da la vuelta a todo el pueblo. Esta está encabezada por las comparsas que bailan y se trasladan mirando hacia atrás porque no le pueden dar la espalda a la Virgen, la cual está flanqueada por sus guardianes, los Qapaq ch'unchu. Durante la procesión, los balcones y techos también se convierten en escenarios con la presencia de los Saqras.

El término Saqra ha sido asociado por la tradición católica a diablo, sin embargo, este término está más relacionado a travieso o diablillo. La comparsa de los Saqras es muy colorida y usan máscaras de animales. Como se han "portado mal", tienen vergüenza de que la Virgen los vea. De esta manera, durante la procesión, los Saqras se colocan en techos y balcones y se esconden con las manos cuando pasa la Virgen ${ }^{15}$. Como dice Gisela Cánepa (1998, p. 62):

Los saqra mantienen un juego de poder con la virgen, porque la tientan a ella y a la gente que asiste a la fiesta, pero al mismo tiempo no son capaces de mirarla de frente. Es por eso que cuando ella recorre en procesión el pueblo, los saqra, subidos en los techos, balcones y postes, se retuercen y se cubren la cara a su paso.

\section{La iglesia}

Esta fiesta es de origen colonial y netamente sincrética. La devoción por la Virgen es muy fuerte y esta es expresada tanto por las misas católicas como a través de la danza.

La iglesia, incluyendo el atrio, es el espacio en que el danzante está con la Virgen de forma más auténtica. La noche del 15 de julio, por ejemplo, se da el alba,

${ }^{15}$ Ver https://www.youtube.com/watch?v=k655N3Yq600 
que es el momento en el que las distintas comparsas bailan frente a la iglesia sin trajes ni máscaras:

\begin{abstract}
Hacia la media noche llega el momento de presentarse ante la virgen que los espera en el atrio del templo, pero no como danzantes de comparsa que disfrazados y enmascarados entregan agradecidos sus bailes a la Mamacha durante días, sino como seres humanos elegantemente vestidos y mostrando sus rostros mortales con nombre y apellido. (Perez en Vásquez, 2014, p. 212).
\end{abstract}

\title{
5. El cementerio
}

El cementerio es un espacio especial y particularmente liminal ya que es donde se encuentra el mundo de los vivos con el mundo de los muertos. En los rituales prehispánicos, a los muertos se les convertía en momias y se les colocaba máscaras, de manera que, cuando los sacaban en procesión, parecían vivos (Jimenez, 1996, p. 38). En Paucartambo, al tercer día de la fiesta, las comparsas se dirigen al cementerio y le rinden culto a sus muertos. Si bien cualquiera puede entrar y ser testigo de lo que allí sucede, el cementerio es un espacio íntimo y de transición de las comparsas.

Cuando llegan, los danzantes se colocan alrededor de las tumbas y mausoleos de los antiguos danzantes del grupo, "se sacan las máscaras y las colocan delante de las tumbas, cantan, bailan, beben y recuerdan a sus compañeros" (Rubio, 2011, p. 224). De esa manera, los danzantes desaparecidos, a través de las máscaras, se hacen presentes, como las momias del pasado, en el espacio-tiempo que se rompe en la celebración.

En el cementerio se baila, se canta y se toma cerveza. La primera vez que estuve en la Fiesta, en el 2002, alguien me dijo que a los muertos les gustaba que se pisen las tumbas, para sentir la vida. Ya en el 2017, fui reprendido por pisar una tumba por ser una falta de respeto. En cualquier caso, el espíritu de ese momento en el cementerio es de celebración de la vida, recordando y respetando la muerte. 
Por otro lado, es uno de los espacios principales de los ritos de pasaje y acciones internas de las comparsas. En el cementerio realizan bautizos de los nuevos integrantes de las comparsas quienes reciben gustosos los latigazos de bienvenida. Este ritual de dolor, en el espacio de los muertos, es sumamente significativo porque está inundado de amor, alegría y celebración. Al mismo tiempo, también es el espacio en el cual se ejecutan los castigos a los danzantes que han tenido algún comportamiento reprobable. Estos castigos son ejemplares -también con golpes y latigazos- y marcan un nuevo comienzo. La afrenta ya fue pagada.

\section{El puente}

El puente Carlos III en Paucartambo es un puente colonial de piedra cuya construcción "en la segunda mitad del siglo XVIII, parece estar ligada al traslado del pueblo y a su consolidación como importante centro administrativo y comercial en la región” (Cánepa, 1998, p. 43), y fue encargado justamente por el Rey Carlos III de España para evitar que los productos e impuestos destinados a la Corona caigan al río Mapacho. En la procesión del tercer día de la fiesta, la Virgen del Carmen se dirige hacia el puente y cuando llega al medio de este, el anda gira para bendecir los cuatro suyos ${ }^{16}$. Hay una versión que cuenta que la Virgen, cansada de ver a sus hijos pelear, decide irse del pueblo. Los danzantes la acompañan rogándole que no se vaya y, a mitad del puente decide parar, bendecir los cuatro suyos y regresar.

\section{La plaza}

La plaza es uno de los lugares principales de performatividad en esta fiesta y se usa de tres formas principales en cada uno de los días de la fiesta.

\footnotetext{
${ }^{16}$ La organización del imperio incaico contaba con cuatro grandes regiones: collasuyo, antisuyo, chinchaysuyo y contisuyo.
} 
Q'onoy

En la noche del 15 acontece el Q'onoy o incendio. Los Qollas han llegado al pueblo para llevarse a la virgen porque afirman que son sus verdaderos guardianes. En la noche, entonces, “incendian” el pueblo. La configuración escénica es circular. La pista alrededor de la plaza es el escenario mientras que el público se coloca dentro de la plaza, mirando hacia afuera y en los alrededores, sobre la vereda, junto a las casas. Toda la acción se desarrolla en desplazamiento en sentido antihorario. Para el incendio, se colocan tres castillos de fuegos artificiales en distintos extremos de la plaza (que no es cuadrada ni rectangular), montones de paja por todo el espacio escénico y los qollas también portan fuegos artificiales. La acción termina cuando se quema el último castillo.

\section{El bosque}

Al día siguiente, los qollas cambian de estrategia. En el medio de la plaza se ha construido un andamio alto donde se colocan con distintos objetos: vasos, bateas, muñecos, banquitas, recipientes, frutas etc. El "público" se coloca alrededor de ese andamio y los qollas empiezan a lanzar los regalos en todas las direcciones desde el andamio y los balcones ubicados alrededor de la plaza. Los qollas, dan regalos para ganarse al pueblo. Miguel Rubio recogió una versión de los Qapaq Ch'unchu que dice que en realidad el andamio es armado como estrategia militar para tener altura y poder ver quién está llegando.

\section{La guerrilla}

La guerrilla determina el final de la Fiesta. En esta se da el enfrentamiento final entre ch'unchus y qollas por el cuidado de la Virgen. Esta se detona cuando la Imilla ${ }^{17}$, esposa del alcalde de los qollas, es raptada por el rey de los ch'unchus,

${ }^{17}$ El personaje de la Imilla es representado por un hombre y tiene la cabeza totalmente cubierta por una tela negra. 
y termina cuando el alcalde de los qollas muere. La configuración espacial es igual a la del Q’onoy: escenario en la pista, danzantes desplazándose en sentido antihorario y "público" alrededor, tanto en los bordes como dentro de la plaza mirando hacia afuera. Por otro lado, durante la guerrilla existe mucha interacción con el público, sobre todo de parte de los qollas y los maqtas que que son muy juguetones, tiran cerveza a los espectadores y queman ají para que ardan los ojos.

\section{Concursos}

En esta fiesta no hay concurso de danzas ni tampoco un escenario destinado para la presentación de las danzas como espectáculo. Sobre este tema, en Paucartambo ocurren dos cosas particulares: la primera es que, durante la década de 1970, había comparsas de campesinos indígenas que bajaban al pueblo y los mestizos (dueños de la fiesta) les permitían presentar sus danzas en un escenario. Cuando en años posteriores, alguien sugirió armar un escenario, los danzantes se opusieron, unos porque decían que bailaban por fe, y otros porque no querían ser confundidos con las comparsas de los indígenas de las comunidades ${ }^{18}$. Es decir, el status social fue muy importante para tomar esta decisión. Sin embargo, los concursos no son ajenos a las comparsas de danzantes de Paucartambo porque estas no solo participan en el concurso Inti Raymi de la región del Cusco, sino que el hecho de haber ganado este concurso le puede dar a una determinada danza o comparsa el prestigio necesario para participar en la fiesta de la Virgen del Carmen en Paucartambo, tal como lo plantea Cánepa sobre la Contradanza:

Si bien la contradanza no está vinculada a ningún relato acerca del origen de la fiesta, ni participa en la guerrilla, su prestigio está basado en el hecho de haber sido ganadora del primer puesto en Concurso Departamental de Danzas Folclóricas en 1968 y, posteriormente, en el

\footnotetext{
18 “Van den Berghe $(1977,217)$ afirma que en 1973, año en que él observó la fiesta, participaban comparsas de campesinos representando comunidades o distritos que llegaban acompañados de un karguyuq mestizo. Es muy importante señalar que en la fiesta se delimitaban muy claramente los espacios, los momentos y funciones de las comparsas del pueblo y las foráneas. Las comparsas de los grupos campesinos indígenas participaban en un concurso de danzas folclóricas para obtener un trofeo, mientras que las comparsas del pueblo, consideradas parte integrante de las ceremonias de la fiesta, no actuaban en el concurso formal, ya que ellas bailan por devoción a la virgen. Las comparsas de campesinos bailaban en un tabladillo para dar un espectáculo a los asistentes." (Cánepa, 1998, p. 55).
} 
festival del Inti Raymi en 1991. Además se valoran la riqueza del vestuario, la complejidad de la coreografía y el status social de los danzantes que la integran. (Cánepa, 1998, p. 63).

Si bien la participación en concursos fuera de la fiesta puede dar prestigio, "la participación en eventos externos a la propia fiesta, (...), no es común entre el resto de comparsas ${ }^{19}$. Algunos grupos incluso critican que las danzas se bailen en contextos no estrechamente vinculados a la devoción por la virgen." (Cánepa, 1998, p. 65).

\section{Algunas consideraciones}

Como dice Schechner (2005), todo ritual tiene un componente de entretenimiento y viceversa, pero habitualmente es el espacio el que determina la intencionalidad del hecho escénico-ritual. En el caso de las danzas de teatralidad andina, su carácter, en gran medida, es determinado justamente por el espacio en el que se presenta, aunque el "producto escénico" sea el mismo. De esta manera, la misma coreografía interpretada en el frontis de la iglesia en el contexto de la fiesta religiosa, tiende más al ritual, mientras que si es presentada en un escenario durante un concurso tiende hacia el entretenimiento. Ambos espacios son igualmente valiosos aunque cumplen con objetivos diferentes que no tienen por qué ser percibidos como excluyentes o contrarios.

Por otro lado, como se puede ver a partir de los ejemplos descritos, un elemento relevante para entender las manifestaciones de teatralidad andina es la confluencia y las distintas posibilidades de relación entre danzantes y no danzantes en el espacio. De esta manera, hay espacios y momentos en los que la interacción es más fluida, como en los cargos o la calle, y otros en los que la comparsa está más ensimismada tanto por lo ritual como por lo espectacular, como en la iglesia o el escenario. Sin embargo, también es común que en las

${ }^{19}$ En este caso, Cánepa se está refiriendo a la danza Qullacha. 
distintas danzas existan personajes cuya misión es cuidar a los danzantes y abrir campo, y, al mismo tiempo, establecer una relación con las personas a manera de juego. En Paucartambo están los Maqt’as, que son transversales a todas las danzas; en la Chonguinada están los Chutos; en la danza de Shapish de Chupaca (Junín) están los Negritos, por ejemplo. Si bien los danzantes se convierten en seres "especiales", al mismo tiempo son parte de una comunidad que comparte sus creencias y su pertenencia, y los asiduos a la fiesta saben bien cuándo y dónde se puede interactuar y cuándo no. Estos encuentros, esta convivencia no siempre es fácil y está atravesada por diversos intereses. Por ejemplo, no es poco común que haya algún nivel de tensión entre turistas buscando el mejor ángulo para tomar la foto, y los fieles que esperan con devoción para poder expresar su fe en la participación de los rituales, o los mismos danzantes que son interrumpidos en sus coreografías.

Los espacios y los distintos momentos de la fiesta tienen sus propios códigos que, como ya mencioné, son conocidos por los asiduos a la misma, pero muchas veces esos códigos son trastocados por aquellos que no los conocen, por un lado, o por personas que utilizan la fiesta ritual y el atractivo de las danzas para otros intereses políticos y económicos, por ejemplo. En las distintas fiestas encontramos empresas que imponen la presencia de su marca o aspirantes a políticos que se valen de la fiesta para ganar votos, pasando también por las municipalidades que buscan aprovechar la fiesta para atraer turistas y generar ingresos para la localidad, en el mejor de los casos, y para sus bolsillos, en otros.

En ese sentido, el hecho de que un mismo acto sea percibido por los participantes de la fiesta en distintos puntos del continuum entre ritual y entretenimiento puede generar tensiones difíciles de conciliar.

Finalmente, el hecho de que estas manifestaciones duren varios días y utilicen distintos espacios con características particulares, fortalece las posibilidades de que se presenten situaciones ambiguas y fronterizas, y determinadas por las circunstancias propias de la liminalidad presentada por Dieguez (2014), que se manifiesta de diversas formas tales como en la confluencia entre lo antiguo y lo contemporáneo; entre la tradición prehispánica y la católica; 
en la construcción y la tensión entre lo mestizo y lo indígena; entre lo cotidiano y lo extraordinario; entre la performance y la vida. Los espacios del pueblo que son transformados en el contexto de la fiesta, son, entonces, tanto protagonistas como testigos de esta liminalidad que seguirá reconfigurándose y recodificándose año tras año.

\section{Referências}

BENZA, Rodrigo. Memoria del $7^{\circ}$ Laboratorio Abierto del grupo Yuyachkani. 2016 (texto no publicado)

CÁNEPA, Gisella. Máscara, transformación e identidad en los andes: la fiesta de la Virgen del Carmen Paucartambo-Cuzco. Lima: PUCP, 1998.

DIEGUEZ, Ileana. Escenarios Liminales. Teatralidades, performatividades, políticas. México, D.F.: Toma, Ediciones y producciones escénicas y cinematográficas, 2014.

JIMENEZ, Arturo. Máscaras peruanas. Lima: Fundación del Banco Continental para el Fomento de la Educación y la Cultura, 1996.

LECAROS-TERRY, Ana Teresa. Los Peregrinos del Señor de Muruhuay. 2001. Tesis (Doctorado), Universidad de Berlín. Disponible en: http://www.diss.fuberlin.de/2001/12/indexe.html. Acceso en: 7 jul. 2020.

MILLONES, Luis. Actores de altura, ensayos sobre el teatro popular andino. Lima: editorial Horizonte, 1992

MINISTERIO DE CULTURA. Resolución Viceministerial No 047-2014-VMPCIC-MC, $2014 . \quad$ Disponible en: https://cdn.www.gob.pe/uploads/document/file/209756/rvm 047-.pdf. Acceso en: 7 jul. 2020.

MUNICIPALIDAD DISTRITAL DE JUNÍN. Manual de Chonguinada. Junín: Municipalidad distrital de Junín, 2010.

RUBIO, Miguel. El cuerpo ausente (performance política). Lima: Yuyachkani, 2008.

RUBIO, Miguel. Raíces y Semillas. Maestros y caminos del teatro en América Latina. Lima: Yuyachkani, 2011.

RUBIO, Miguel. O grande teatro de Paucartambo. Sala Preta, São Paulo, vol. 16, n.1, 2016. 
SCHECHNER, Richard. Performance Theory. Taylor \& Francis e-library, 2005.

VASQUEZ, Cecilia. Fiesta de la Mamacha Carmen en Paucartambo, Cusco. Lima: Cecilia Vasquez, 2014

VASQUEZ, Chalena. Educación por el Arte, Serie 2 para estudiantes de Secundaria. Historia del Arte Peruano Fascículo 3: ritos y fiestas: origen del teatro y la danza en el Perú. Lima: Ministerio de Educación, 2007. Disponible en: http://www.minedu.gob.pe/pdf/ed/historia-del-arte-peruano.pdf. Acceso en: 10 jul. 2020

Recebido em: 11/07/2020

Aprovado em: 09/08/2020 